\title{
Balanço energético da produção de etanol a partir da cana-de açúcar e as- pectos da produção brasileira atual
}

\author{
Romário Victor Pacheco Antero ${ }^{\mathrm{a}}$, Damina Beatriz da Silva*, Sarah Silva Brum ${ }^{\mathrm{a}}$, Ailton Teixeira do Vale ${ }^{\mathrm{a}}$
}

a Unidersidade de Brasília (UNB), Brasil

*Autor correspondente (damisb@uft.edu.br)

\section{N F O}

Keywords

ethanol

biofuel

energetic balance

sugarcane

Palavras-chaves etanol

biocombustível balanço energético cana de açúcar

\begin{abstract}
A B S T R A C T
Energy balance of ethanol production from sugarcane and aspects of current Brazilian production Interest in alternative energy sources has increased in recent times, especially those considered essential for the mitigation of greenhouse gas emissions. In this regard, biofuel production has been prominent worldwide, with ethanol being one of the main energy alternatives for the future. However, similar to what happens with every energy resource, ethanol also demands energy for its production. Thus, the objective of this work was to analyze the energy balance of ethanol production from sugarcane, considering the energy-consuming activities. Also presented are the main characteristics related to ethanol production, the worldwide production cycle, the main producers, data on the current Brazilian sugarcane and ethanol productivity (2017/2018 crop), world ethanol production and the main destinations of Brazilian ethanol production. To this end, different articles and scientific papers published at the national and international level on the subject under discussion were consulted, through a study design carried out through qualitative and quantitative analysis of materials obtained in a literature review.
\end{abstract}

\section{R E S U M O}

Nos últimos tempos têm crescido o interesse em fontes alternativas de energia, principalmente aquelas apontadas como essenciais para a mitigação das emissões de gases responsável pela problemática do efeito estufa. Nesse aspecto, a produção de biocombustíveis tem se destacado em todo o mundo, sendo o etanol apontado como uma das principais alternativas energéticas para o futuro. No entanto, semelhante ao que ocorre com todo recurso energético, o etanol também demanda energia para a sua produção. Dessa forma, o objetivo deste trabalho foi analisar o balanço energético da produção de etanol de primeira geração a partir da cana-de-açúcar, considerando as atividades consumidoras de energia. Também são apresentadas as principais características relacionadas à produção do etanol de primeira geração, o ciclo produtivo em escala mundial, os principais produtores, dados sobre a produtividade brasileira atual de cana-de-açúcar e etanol (safra 2017/2018), a produção mundial de etanol e os principais destinos da produção brasileira de etanol. Para isso, foram consultados diferentes artigos e trabalhos científicos publicados a nível nacional e internacional sobre o tema em debate, através de um delineamento de estudos realizados por meio de análises qualitativas e quantitativas de materiais obtidos em revisão bibliográfica. 


\section{INTRODUÇÃO}

A sustentabilidade ambiental é um conceito que ganhou ênfase na última década devido às constantes preocupações sobre o uso massivo de combustíveis fósseis e seus possíveis efeitos sobre as mudanças climáticas. Sob esse ponto de vista, em 2016 as Nações Unidas lançaram a Agenda para o Desenvolvimento Sustentável 2030, a qual visa orientar e estimular ações voltadas ao aumento substancial da quantidade de produção de energia a partir de fontes renováveis (Unit Station, 2015). Nesse contexto, o aumento da produção de energia a partir de fontes renováveis deve se tornar um marco para todos os países (Handler et al., 2016), influenciando o financiamento de pesquisas que visem o aumento do desenvolvimento de produtos a partir de fontes renováveis.

Do total da demanda global de energia, $40 \%$ são consumidos sob a forma de combustíveis líquidos (Nanda et al., 2015), e espera-se que os veículos elétricos representem um quarto dos carros até 2040, diminuindo quase 13 milhões de barris (2.067 milhões de litros) por dia de petróleo bruto (BNEF, 2016). Nesse aspecto, os biocombustíveis assumem papel essencial, sendo o etanol a alternativa predominante (Handler et al., 2016). Nesse cenário de empoderamento dos biocombustíveis e do uso de fontes renováveis de energia, o Brasil destaca-se por possuir 39\% de sua matriz energética composta por combustíveis renováveis (EPE, 2017). Dentre esses destaca-se o etanol produzido a partir da cana de açúcar, com o estabelecido processo de produção de primeira geração em larga escala (Moraes; Zaiat e Bonomi, 2015). Toda essa produtividade começou a se desenvolver no decorrer da década de 1970 como resultado da crise petrolífera (Coelho et al., 2006) e tornou a utilização do etanol ao longo de décadas uma das principais fontes energéticas para o futuro (Oliveira; Serra e Oliveira, 2014).

No Brasil, o etanol de cana-de-açúcar tem promovido o desenvolvimento rural, a diversificação das fontes de energia, menor dependência das importações de petróleo e redução de gases de efeito estufa (GEE) (Coelho et al., 2006). Embora a produção de etanol tenha crescido e se adequado como uma fonte promissora de combustível, sua produção demanda energia em todo o ciclo produtivo. Dessa forma, para se adequar como uma fonte alternativa e viável economicamente, é necessário que, durante a produtividade, a energia gasta no processo seja compensada ao final das operações. Assim, para se ter noção da viabilidade do processo e eficiência do ponto de vista energético é necessário realizar seu balanço energético.
O balanço energético compreende a relação entre a energia investida na produção de determinado produto (input) e a energia obtida na sua combustão, quando se referindo à produção de combustíveis e biocombustíveis (Chechetto e Siqueira; Gamero, 2010; Gazzoni et al., 2009; Urquiaga e Boodey, 2005). Trata-se de um parâmetro que verifica a quantidade de energia fóssil investida e a energia obtida por durante a produção do combustível. Numericamente, seu valor é dado pela relação entre a energia obtida com o combustível e a energia despendida durante a produção. Valores acima de 1 traduzem que a energia obtida é maior que a energia gasta, assim, o balanço é positivo e a fonte viável. Valores inferiores a 1 revelam um gasto maior na produção do combustível do que o obtido durante a sua utilização, referindo-se dessa forma, a um balanço energético negativo (Oliveira; Serra e Oliveira, 2014).

Segundo Gazzoni et al., (2009), o balanço energético pode ainda ser considerado uma importante ferramenta a partir do qual é possível aperfeiçoar a utilização de insumos para determinado cultivo e os parâmetros necessários para a eficiência produtiva de diversos sistemas, constituindo-se em uma importante ferramenta de análises econômicas. Portanto, é possível considerar o balanço energético como um mecanismo essencial para determinar os pontos de gasto energético, fundamentando-se na busca por tecnologias poupadoras de energia (Campos e Campos, 2004). De maneira geral, para avaliar os méritos da substituição da gasolina pelo etanol, uma análise do equilíbrio energético e das emissões evitadas de gases de efeito estufa (GEE) deve ser realizada com a análise do ciclo de vida. As diferentes matérias-primas para a produção de etanol também devem ser comparadas em tais termos, bem como a eficiência do uso da terra (Goldemberg; Coelho e Guardabassi, 2008; Larson, 2006).

Diante do exposto, a partir de um minucioso levantamento em diferentes fontes na literatura, o presente trabalho descreve os principais fatores relacionados ao balanço energético do etanol, considerando os gastos energéticos para o cultivo da planta, transporte e para o processo produtivo. Além de abordar e discutir os principais parâmetros envolvidos no balanço energético da produção do etanol de primeira geração, o artigo também apresenta os dados da produtividade brasileira de etanol na safra 2017/2018. Inicialmente são apresenta-se uma rápida abordagem sobre a produção de etanol a partir de diferentes precursores e as metodologias de obtenção disponíveis. Seguidamente é abordada a produção brasileira atual de cana de açúcar, as estimativas observadas por região e a produtividade 
brasileira de etanol em comparação com outros países. Finalizando, apresenta-se uma revisão abrangente e comparativa entre diversos cálculos para o balanço energético verificados na literatura.

\section{ABORDAGEM E METODOLOGIA}

A metodologia aplicada considerou as informações sobre os atuais métodos para produção de etanol de primeira geração a partir da comparação da produção de etanol de cana-de-açúcar no Brasil e demais culturas mundiais, com base na produtividade média. Os dados apresentados foram obtidos a partir de uma extensa revisão bibliográfica utilizando-se as palavras chaves "etanol, balanço energético, cana de açúcar e biocombustíveis". No balanço energético da produção e uso de etanol, destacou-se as principais atividades envolvidas no processo, bem como os gases de efeito estufa (GEE) e o ciclo de vida da produção.

\section{PRODUÇÃO DE ETANOL DE PRIMEIRA GERAÇẪo}

Diversas matérias primas podem ser utilizadas na produção de etanol, as quais podem ser divididas em três categorias: sacaríneas, amiláceas e celulósicas. Na primeira classe estão envolvidas as fontes que possuem o açúcar sacarose (cana-de-açúcar, sorgo sacarino, beterraba, entre outros). No segundo grupo (amiláceos) têm-se os produtos compostos por amido (mandioca, cereais, sorgo, batata, etc.). Em última categoria têm-se as matérias primas celulósicas, na qual o etanol é produzido a partir da celulose existente em sua composição, destacando-se o eucalipto, bagaço de cana, casca de arroz, entre outros (Oliveira; Serra e Oliveira, 2014), o chamado etanol de segunda geração. De maneira geral a grande maioria do etanol produzido no mundo é de cana-de-açúcar, principalmente no Brasil e milho nos Estados Unidos (que em conjunto representam 35,4 milhões de metros cúbicos, cerca de $72 \%$ da produção mundial) (Goldemberg; Coelho e Guardabassi, 2008). Devido à sua composição, a cana de açúcar se destaca como uma das principais biomassas para aplicações com fins energéticos, principalmente no Brasil, como é abordado nos tópicos seguintes. A cultura se destaca entre as demais empregadas na produção do etanol por apresentar o maior rendimento da produção por unidade de área cultivada como se observa na figura.1.

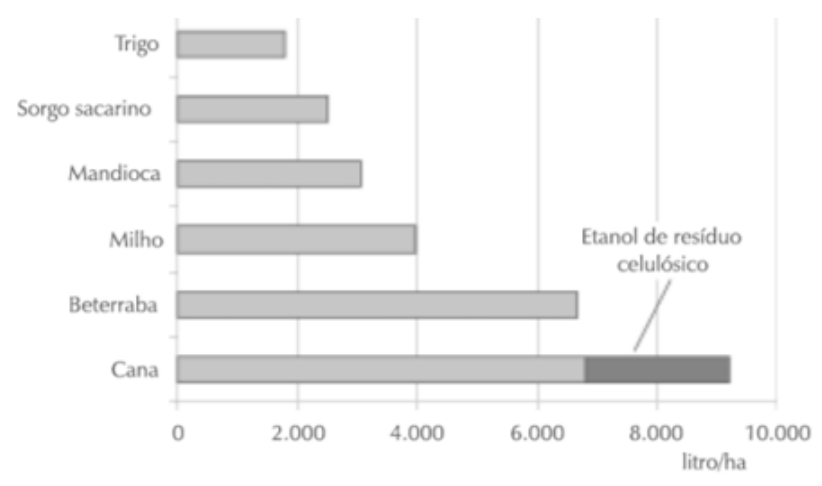

Figura 1 - Produtividade média do etanol por área para diferentes culturas (Oliveira, 2010).

Dentre as formas de obtenção de etanol, a utilização da biomassa açucarada (cana e beterraba) possui duas etapas a menos que as outras formas, sendo excluída a fase de hidrolise ácida ou enzimática (figura 2), o que torna o balanço energético para esse tipo de produção melhor que as demais. No entanto, diversos outros fatores devem ser considerados em cada sistema de produção energética para se estimar o real balanço energético do ciclo produtivo do etanol.

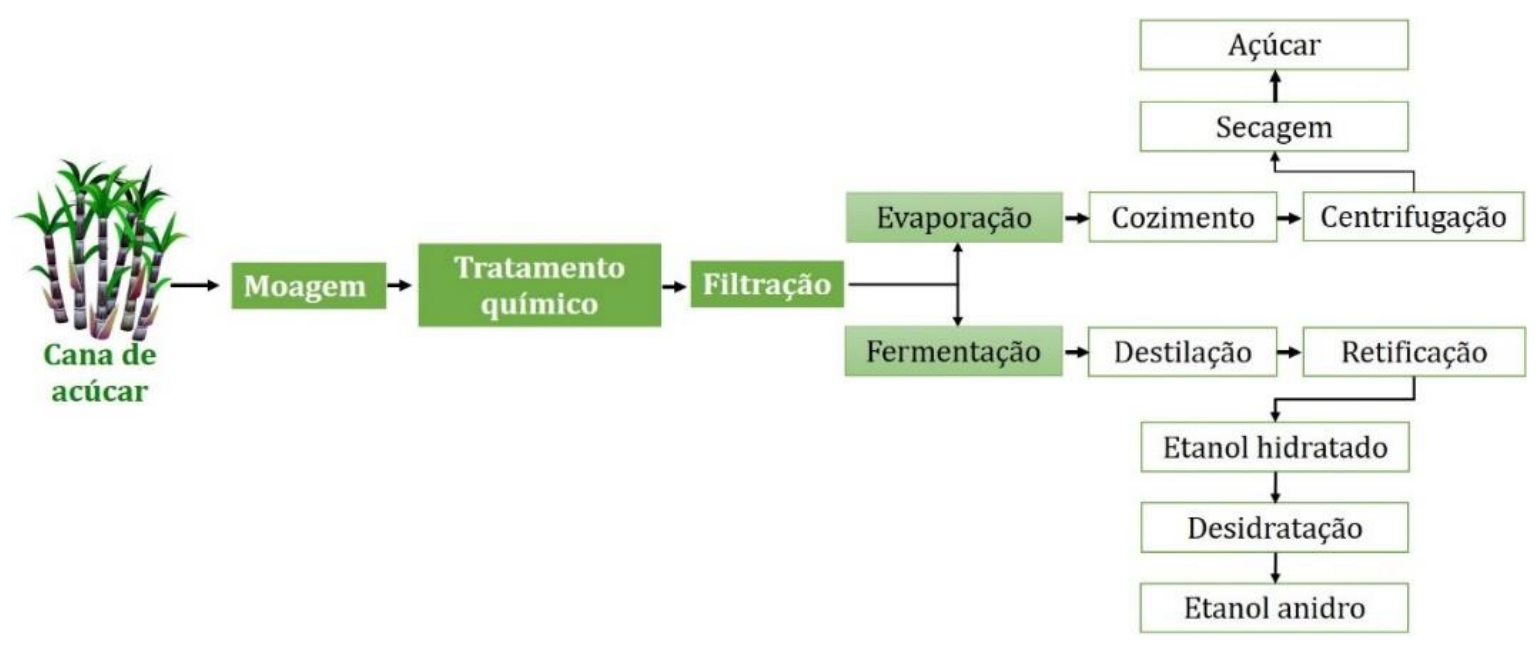

Figura 2 - Fluxograma para a produção de açúcar e etanol a partir da cana. Adaptado de BNDS (2008). 
A partir do fluxograma ilustrado na figura 2, observa-se que inicialmente a cana é lavada e transportada para o sistema de preparo e extração do caldo, que contém a sacarose, sendo posteriormente separado da fibra (bagaço), o qual segue para a planta da usina e é empregado como combustível. $\mathrm{O}$ caldo obtido passa por uma série de processos, tais como calagem, aquecimento e decantação. Posteriormente é evaporado para ajuste da concentração de açúcares e, eventualmente misturado com o melaço, originando o mosto. Este seguirá para as dornas de fermentação, onde será misturado com leveduras e fermentado por um período de 8 a 12 horas, dando origem ao vinho, com concentração de $7 \%$ a $10 \%$ de álcool. Ao final do processo as leveduras são recuperadas mediante centrifugação e se inicia o processo de destilação, na qual o etanol é recuperado na forma hidratada, com aproximadamente $96^{\circ} \mathrm{GL}$. Nesse processo obtém-se também a vinhaça ou vinhoto residual, geralmente numa proporção de 10 a 13 litros por litro de etanol hidratado (Oliveira, 2010).

\section{Produtividade brasileira atual de cana de açú- car}

Nos últimos anos a cana-de-açúcar vem sendo considerada uma das maiores apostas para o setor de biocombustíveis devido à sua versatilidade para produção de produtos concomitante ao etanol. Além da produção do biocombustível e açúcar, as unidades produtoras têm se concentrado na busca de maior eficiência e sustentabilidade dos processos, focando também na geração de energia elétrica, o que vem auxiliando na redução dos custos e contribuindo para a sustentabilidade da atividade (CONAB, 2017). Nesse cenário, o mercado para a cana-de-açúcar está sustentado principalmente na produção de açúcar e etanol, caracterizado como setor sucroenergético, do qual $47 \%$ da cana plantada é destinada à produção de açúcar e $53 \%$ é destinada à produção de etanol, conforme se observa no fluxograma da figura 3 (CONAB, 2016; DEPEC, 2017).

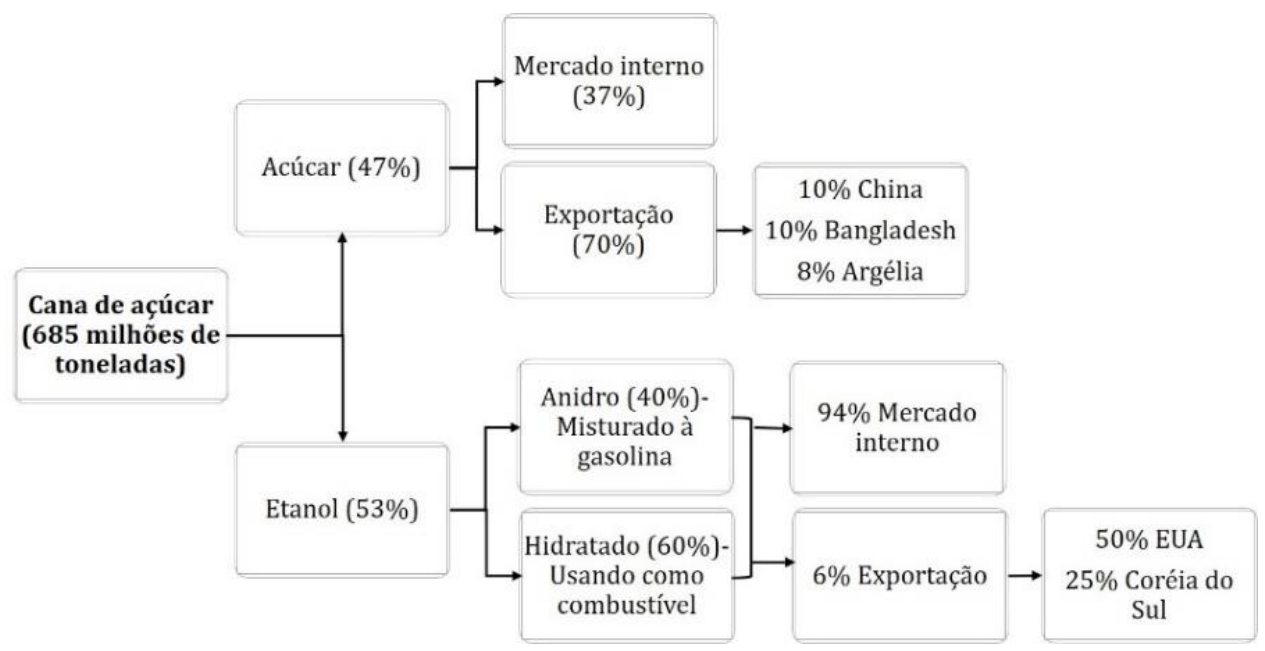

Fonte: Adaptado (CONAB, 2016; DEPEC, 2017).

Figura 3 - Fluxograma detalhado para o mercado consumidor de cana-de-açúcar e respectivos mercados de destinação.

Nas últimas décadas observou-se um crescimento constante do setor sucroenergético e, quadro após a os baixos valores observados em 2011/2012. Nesse contexto, estimativas apontam um aumento na produção de cana-de-açúcar de $55 \%$ entre 2010/2011 a 2022/2023, com expansão de área total de $43 \%$, ou 3,95 milhões de hectares (FIESP/ICONE, 2012). Em uma estatística mundial, o Brasil é apontado como o maior produtor de canade-açúcar e dados recentes para a safra 2017/2018 demonstram uma produtividade estimada para a temporada de $73.728 \mathrm{~kg} / \mathrm{ha}$. O aumento observado em relação à safra anterior - aproximadamente $1,5 \%$ - é resultado do aumento da produtividade demonstrado pelas lavouras da região Norte-Nordeste $(7,5 \%)$ e, em menor escala, na região Centro-Sul, principal produtora nacional $(1,3 \%)$, comparado com os valores observados na safra passada figura 5). Esses efeitos produtivos estão relacionados às condições climáticas que se mostraram favoráveis a partir de outubro de 2016, favorecendo o desenvolvimento das lavouras e o investimento tecnológico das unidades com o uso de variedades genéticas mais produtivas e melhores tratos culturais. 


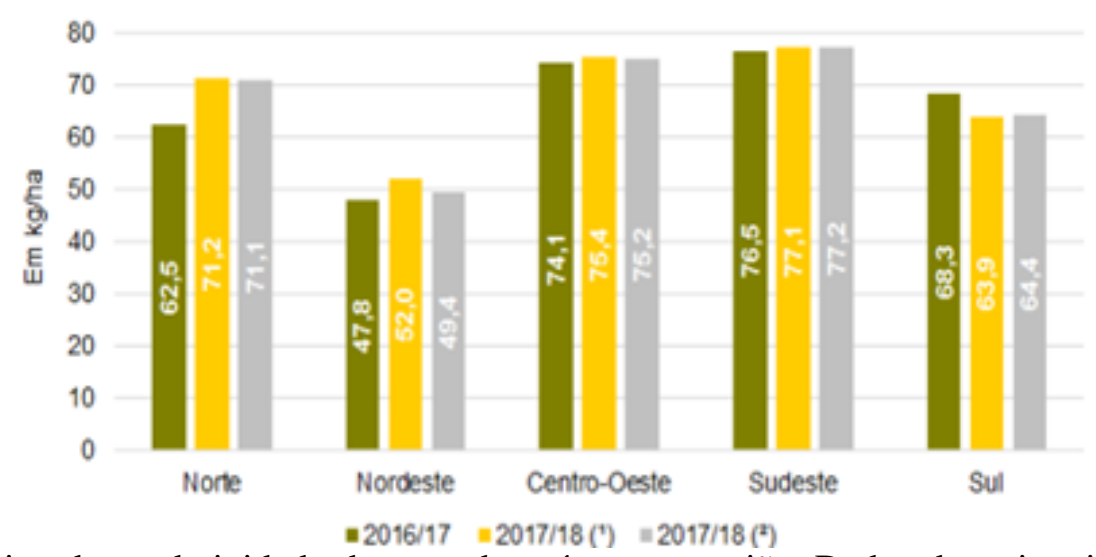

Figura 4 - Estimativa de produtividade de cana-de-açúcar por região. Dados de estimativa: agosto de 2017 (CONAB, 2016)

Tratando-se da produtividade, os dados do CONAB $(\mathrm{CONAB}, 2016)$ também apontam que estimativa de produção de cana-de-açúcar, na safra 2017/18, apresentou um decréscimo de 1,7\%, em relação à safra anterior. Isso equivale a uma produção de 646,34 milhões de toneladas de cana-de-açúcar, ante aos 657,18 milhões da safra 2016/17. Mesmo com a expectativa de melhoria da produtividade, a na redução de área, observada nos principais estados produtores da Região Centro-Sul, será responsável pela expectativa de menor produção, quando se compara com o período anterior. Esses dados se mostram em desacordo com estimativas levantadas pela Federação das Indústrias do Estado de São Paulo no compendio Outlook Brasil 2022Projeções para o agronegócio, no qual é apontado um aumento de 1,3\% ao ano na média brasileira da área destinada à produtividade de cana-de-açúcar (FIESP/ICONE, 2012).

\section{Produtividade Brasileira Atual de Etanol}

O Brasil se destaca atualmente como referência mundial em tecnologia sucroalcooleira, sendo atualmente o segundo maior produtor mundial de etanol (superado em 2006 pelos EUA) e o único país onde os biocombustíveis são estritamente competitivos com derivados do petróleo. Dados elaborados e disponibilizados em 2017 pelo Departamento de Pesquisas e Estudos Econômicos (DEPEC) (DEPEC, 2017), por exemplo, apontaram o país como responsável por aproximadamente $27,7 \%$ do etanol produzido mundialmente, estando atrás somente dos EUA que eram responsáveis por aproximadamente $56,8 \%$ da produção mundial, como se verifica na figura 5 .

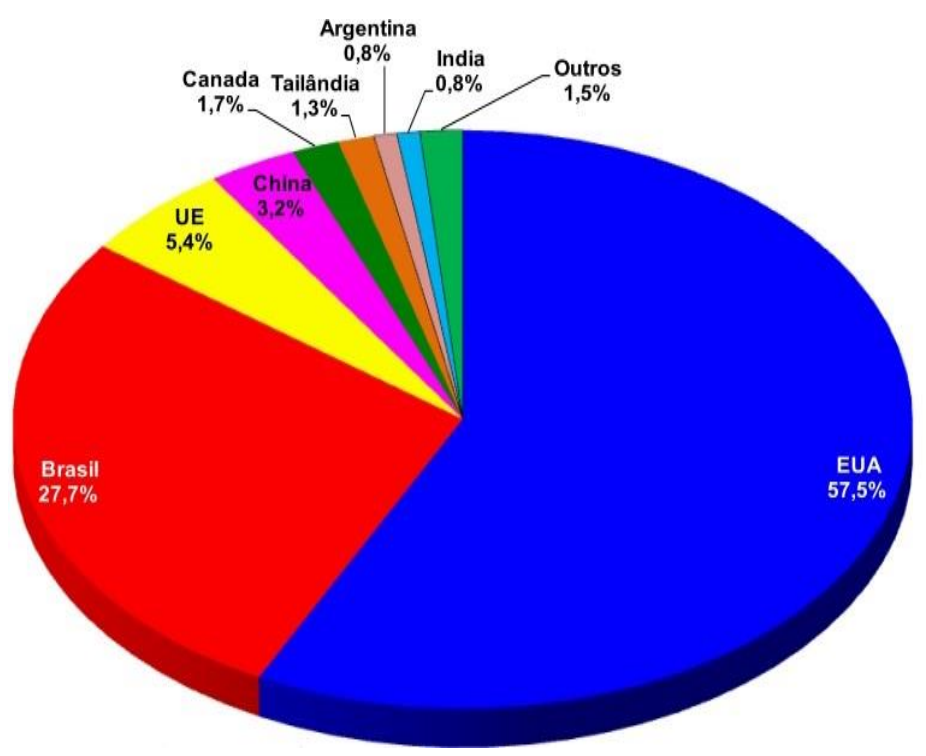

Figura 5 - Produção mundial de etanol (DEPEC, 2016). 
Parte da produtividade brasileira de etanol é destinada à exportação. $\mathrm{O}$ mercado, juntamente com $\mathrm{o}$ de açúcar, movimenta atualmente cerca de 5,7\% das exportações. Do contingente de etanol comercializado internacionalmente, os EUA obtêm a maior parte, como se observa na Fig. 6. O país importa etanol brasileiro e comercializa via países do Caribe, como El Salvador, Jamaica e Costa Rica. Durante a safra $2014 / 15$ a produtividade brasileira de etanol consolidou-se em 28,66 bilhões de litros.
Para a safra 2015/2016 houve um aumento de 156,94 milhões de litros, ou $0,5 \%$. O etanol anidro (empregado na mistura com a gasolina) aumento de 355,17 milhões de litros, chegando a 12,08 bilhões, 350 milhões de litros a mais que a safra anterior. Para o etanol hidratado (empregado nos veículos flex fuel) as estimativas foram negativas, com uma redução de $1,2 \%$ em relação à safra passada $(\mathrm{CO}-$ NAB, 2015).

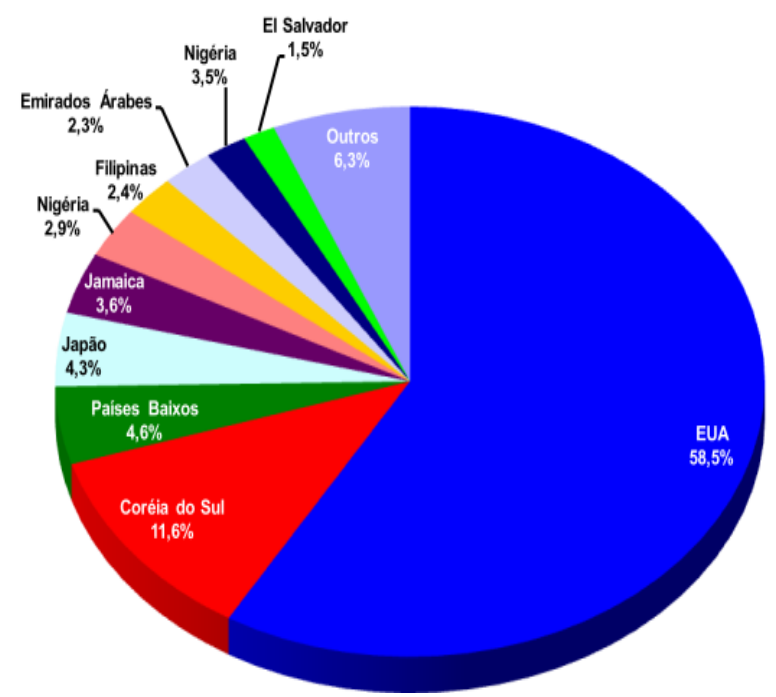

Figura 6 - Países de destino das exportações brasileiras de etanol. Fonte: DEPEC (2015).

Comparada com as safras 2015/2016 e 20162017, a produção brasileira de etanol total no segundo levantamento da safra 2017/18 foi inferior. Nesse contexto, observou-se uma produtividade em litros de aproximadamente 26,12 bilhões, inferior em $6,1 \%$ às safras anteriores, que superaram 27,81 bilhões de litros. Esse decréscimo apresentou relação direta com o aumento observado no consumo da gasolina em 2016, respaldando os preços do etanol anidro nas misturas de combustível, além dos preços favoráveis do açúcar que incentivaram a produção desta commodity em detrimento ao etanol. Neste sentido, a produção do etanol anidro na safra 2017-2018, contemplou um aumento de $0,2 \%$ em relação à safra passada, saindo de 11,07 bilhões de litros para 11,09 bilhões de litros (CONAB, 2016).

As estimativas negativas no avanço da produção brasileira de etanol, bem como a regressão da produtividade no ano de 2016 também foram reportadas em dados publicados pela Renewable Fuels Association no compendio intitulado "Building Prtnerships- Growing markets 2017 ethanol industry outlook". Durante esse período, o Canadá e o Brasil permaneceram como os principais exporta- dores da indústria de etanol americana, os quais receberam aproximadamente metade da produção americana (RFA, 2017). As exportações para o Brasil aumentaram em decorrência dos preços relativamente altos do açúcar, tornando-se necessário o aumento da produtividade para suprir a demanda doméstica. Na safra 2017-2018 observou-se uma produtividade de 26,12 bilhões de litros, redução de apenas $6,1 \%$ em razão da preferência pela produção de açúcar. Já para a produção de etanol anidro, empregado na mistura com a gasolina, ocorreu um aumento de $0,2 \%$, alcançando 11,1 bilhões de litros, influenciada pela manutenção do consumo de gasolina em detrimento ao etanol hidratado (CONAB, 2016).

Considerando a enorme produtividade brasileira de cana-de-açúcar e mais precisamente para a produção de etanol que consome mais de 50\% da produção, a realização do balanço energético visando estabelecer os fluxos de energia, identificando a demanda total e eficiência é importante ferramenta para aprimoramento das técnicas e busca por metodologias inovadoras na cadeia produtiva, de maneira a poupar e até substituir o uso de fontes de energia não renováveis. Dessa forma, para garantir a sustentabilidade dos biocombustíveis é necessário 
confirmar que os gastos exigidos para a produtividade do etanol sejam compensados pelas atividades desenvolvidas com o produto final, considerando nesse aspecto, por exemplo, que a que a energia produzida a partir do etanol seja maior que a energia consumida em sua produção.

\section{Balanço energético da produção e uso de etanol}

Para a realização do cálculo do balanço energético, inicialmente, é necessário levantar todos os parâmetros relacionados desde o cultivo até o processamento final do biocombustível (Oliveira, 2010). Nesse aspecto, Oliveira; Serra e Oliveira (2014) também levam em consideração as chamadas atividades consumidoras de energia, segundo os quais, são fatores primordiais para a realização dos cálculos envolvidos na produção do etanol.
Além desses fatores, o balanço energético também deve considerar emissões evitadas de gases de efeito estufa (GEE) e uma análise detalhada do ciclo de vida. As diferentes matérias-primas para a produção de etanol também devem ser comparadas em tais termos, bem como a eficiência do uso da terra (Goldemberg; Coelho; Guardabassi, 2008).

\section{Atividades consumidoras de energia}

Na produção de etanol o consumo de energia na cadeia produtiva pode ser resumido em duas principais categorias como sugerem Oliveira, Serra e Oliveira, (2014). Segundo os autores, independente da cadeia produtiva, primeiramente antes da análise do balanço energético é necessário considerar a energia gasta na produção, a qual pode ser resumida conforme detalhado na tabela 1 .

Tabela 1 - Atividades consumidoras de energia na produção de etanol.

\begin{tabular}{l|l}
\hline \multicolumn{1}{c}{ Produção Agrícola } & \multicolumn{1}{c}{ Processo Produtivo } \\
\hline 1. Produção, transporte e aplicação de fertilizante. & 1. Edificações \\
2. Mão de obra & 2. Produção e Transporte de mercadorias \\
3. Transporte de matéria prima máquinas agrícolas & 3. Equipamentos \\
& 4. Eletricidade \\
& 5. Mão de obra \\
& 6. Transporte entre as fases de produção \\
& 7. Calor para destilação \\
& 8. Transporte do produto até o consumidor \\
\hline
\end{tabular}

Fonte: Oliveira; Serra e Oliveira (2014)

\section{Balanço Energético do etanol da cana de açúcar}

O primeiro balanço energético calculado para a produção de cana-de-açúcar em condições brasileiras foi publicado por volta de 1978, período anterior à produção de veículos que empregavam etanol hidratado. Esse estudo serviu como ponto de partida para estudos posteriores publicados por volta de 1993, os quais sempre apresentaram resultados muito baixos ou negativos devido ao grande consumo de fontes fósseis. Este estudo serviu como base para os trabalhos mais recentes, os quais demonstram melhoria no balanço energético devido à substituição de mais de $50 \%$ da energia fóssil pelo uso do bagaço de cana.

Em trabalho publicado em 2005 (Urquiaga, Alves e Boodey, 2005) com base na produtividade média de cana-de-açúcar no estado de São Paulo (84 t.ha ${ }^{-1}$ ), produção de etanol próximo a 86 litros/t de cana fresca e valor calorífico para o etanol de 22,3 MJ.L - $^{-1}$ ficou demonstrado que a produção total de energia no etanol para esses valores soma 161,1 GJ.ha' ${ }^{-1}$. Tomando esses dados como referência para a produção brasileira de etanol, fica demonstrado pela tabela 2 que os ingressos de energia fóssil necessários no balanço energético da produção do etanol de primeira geração, equivale a 8,06 GJ.

Tabela 2 - Balanço energético para a produção de etanol de cana-de-açúcar sob condições brasileiras.

\begin{tabular}{ll}
\hline Rendimento (colmos de cana) & $\mathbf{8 4 , 0 ~ t}$ \\
\hline Produção de etanol & 7.224 1/t \\
$\begin{array}{l}\text { Máquinas agrícolas e transporte à } \\
\text { usina }\end{array}$ & 5,6 \\
Fertilizante/pesticidas & 7,23 \\
Mudas/toletes & 0,48 \\
Insumos na Usina ${ }^{1}$ & 0,62 \\
Equipamentos e prédios & 6,03 \\
Total & 19,98 \\
Energia produzida no etanol & $161,10 \mathrm{GJ}$ \\
\hline $\begin{array}{l}\text { Balanço energético (Energia Ge- } \\
\text { rada/ Energia fóssil investida). }\end{array}$ & $\mathbf{8 , 0 6}$ \\
\hline
\end{tabular}

A partir da tabela 2 observa-se que os maiores gastos energéticos se relacionam ao uso de fertilizantes e pesticidas, seguidos por manutenção, desenvolvimento predial e por último, máquinas agrícolas e transporte. Em relação a esses dados, Campos e Campos, (2004) relatam que a produção e aplicação de agrofármacos devem representar uma 
pequena parcela da energia empregada na agricultura. Segundo esses autores, nos EUA a produção e aplicação desses produtos representam pouco mais de $5 \%$ do total de energia utilizada, o que representa $0,2 \%$ do total de consumo de energia. Por outro lado, os autores estimaram que na agricultura brasileira utiliza-se $21 \%$ de sua energia na forma de combustíveis, $58 \%$ na forma de fertilizantes, $14 \%$ na forma de agrotóxicos e 6,8\% para irrigação, transporte e outros. Para estes dados, os autores não consideraram a energia embutida nas máquinas.

Em trabalho mais detalhado, Santos e Santos (2009) fazendo uma análise da viabilidade energética gasta na produção de etanol em microdestilarias quantificaram a energia gasta pela produtividade da cana em quilocaloria por tonelada de cana (kcal/TC). Os autores apresentaram uma análise mais detalhada, abordando os gastos deste o setor agrícola até o setor industrial. As atividades identificadas pelos autores como consumidoras de energia e seus respectivos gastos por tonelada de cana no setor agrícola são expressos na tabela 3 , na qual é possível observar que os maiores gastos são derivados da utilização de insumos agrícolas e pelo setor de transporte.

Tabela 3 - Energia consumida no setor agrícola para obtenção do etanol por tonelada de cana-de- açúcar.

\begin{tabular}{lc}
\hline Processos agrícolas & $\begin{array}{c}\text { Energia consumida } \\
\text { (kcal) }\end{array}$ \\
\hline Atividade & 5.869 \\
Transportes & 2.087 \\
Fertilizantes (NPK) & 25.784 \\
Calcário & 2.938 \\
Herbicidas & 3.489 \\
Mudas & 1.787 \\
Caminhões e Tratores & 20.658 \\
Implementos & 3.826 \\
\hline Total & $\mathbf{6 6 . 4 3 8}$ \\
\hline
\end{tabular}

Fonte: Adaptada de Santos e Santos (2009).

Outra análise realizada pelos autores refere-se aos gastos exigidos no setor industrial, responsável por um consumo ainda maior que o necessário no setor agrícola e apresentando uma diferença superior a $23,584 \mathrm{kcal}$. Os dados completos estão detalhados na tabela 4 .

Os dados registrados individualmente pelos autores permitem observar que, o gasto total de energia fóssil inserida na produção de etanol de uma tonelada de cana-de-açúcar é de $157.547 \mathrm{kcal}$. Os mesmos consideram a geração de 85 litros de etanol por tonelada de cana. Esse valor seria responsável pela geração de $383.394 \mathrm{kcal}$ de energia pelo etanol e $79.160 \mathrm{kcal}$ pela queima do bagaço, totalizando uma produtividade de $462.554 \mathrm{kcal}$ de energia a partir de 1 tonelada de cana, valores responsáveis por um balanço energético aproximado de 3,15.

Tabela 4 - Energia consumida no setor industrial para a obtenção do etanol por tonelada de cana-deaçúcar.

\begin{tabular}{lc}
\hline Atividade & $\begin{array}{c}\text { Energia consumida } \\
\text { (kcal) }\end{array}$ \\
\hline Queima de lenha & 19.433 \\
Energia elétrica & 19.074 \\
Lubrificantes & 170 \\
Edificações & 35.239 \\
Equipamentos & 11.634 \\
pesados & 4.472 \\
Equipamentos Leves & $\mathbf{9 0 . 0 2 2}$ \\
\hline Total & \\
\hline
\end{tabular}

Fonte: Adaptada de Santos e Santos (2009)

Oliveira, (2010) em trabalho mais abrangente e comparativo entre a produção de etanol a partir da cana e do milho encontraram um valor de 8,3 para uma produtividade de 86 litros por tonelada. Para os cálculos o autor levou em consideração as usinas que entraram em operação a partir de 2001, nas quais as unidades de processamento de cana utilizam turbogeradores acionados por turbina multiestágios e equipamentos mais potentes. Em tais usinas, segundo Lamonica (2010), do potencial térmico do combustível consumido, $3,5 \%$ é transformado em eletricidade, outros 3,5\% são transformados em trabalho mecânico e $67,2 \%$ são transformados em energia térmica, que por sua vez é empregada na produção de açúcar/álcool (Lamonica, 2010; Oliveira, 2010). A partir dessa premissa, o autor apresentou um balanço de energia proveniente da produção de etanol através da cana conforme pode ser verificado na tabela 5 , com projeção até o ano de 2020.

Tabela 5 - Balanço de energia na produção do etanol da cana $(\mathrm{MJ} / \mathrm{tc})$.

\begin{tabular}{lcc}
\hline $\begin{array}{c}\text { Componente do } \\
\text { balanço energético }\end{array}$ & $\mathbf{2 0 0 5 / 2 0 0 6}$ & $\begin{array}{c}\text { Projeção } \\
\mathbf{2 0 2 0}\end{array}$ \\
\hline $\begin{array}{l}\text { Produção e transporte } \\
\text { de cana }\end{array}$ & 210,2 & 238,0 \\
Produção de etanol & 23,6 & 24,0 \\
Input fóssil (total) & 233,8 & 262,0 \\
$\begin{array}{l}\text { Etanol } \\
\text { Excedente de bagaço }\end{array}$ & 1926,0 & 2060,0 \\
$\begin{array}{l}\text { Excedente de } \\
\text { eletricidade }\end{array}$ & 82,8 & 9,0 \\
\hline $\begin{array}{l}\text { Output renovável } \\
\text { (total) }\end{array}$ & $\mathbf{2 1 8 5 , 0}$ & $\mathbf{3 0 3 2 , 0}$ \\
\hline
\end{tabular}

Fonte: Adaptado de Oliveira (2010). 
O diferencial do trabalho apresentado por Oliveira (2010) está no fato do autor considerar no balanço energético as emissões dos gases responsáveis pelo efeito estufa (GEE). Assim, a partir desses dados e aqueles destacados na Tabela 4, o autor chegou ao balanço energético médio do etanol obtido pelo processamento da cana-de-açúcar, comparando-o com os resultados observados na produção de etanol a partir do milho (Tabela 6).

Tabela 6 - Balanço energético médio total para a produção de etanol a partir das culturas de cana e milho.

\begin{tabular}{l|c|c}
\hline \multicolumn{1}{c|}{$\begin{array}{c}\text { Componente do } \\
\text { balanço energético }\end{array}$} & \multicolumn{2}{|c}{ Valores } \\
\cline { 2 - 3 } & Cana & Milho \\
\hline $\begin{array}{l}\text { Produtividade } \\
\text { Balando de Energia } \\
\text { (kcal input:output) }\end{array}$ & $1: 3,24$ & $1,29: 1$ \\
Emissão de GEE & $33,6 \mathrm{~g}$ & $84,9 \mathrm{~g}$ \\
$\mathrm{CO}_{2} / \mathrm{MJ}$ & $\mathrm{CO}_{2} / \mathrm{MJ}$ \\
\hline $\begin{array}{l}\text { Balanço energético } \\
\text { médio }\end{array}$ & $\mathbf{8 , 3}$ & $\mathbf{1 , 4}$ \\
\hline
\end{tabular}

Nota: *Gases de ${ }^{\text {efeito }}$ estufa originados durante a produção do etanol (Oliveira, 2010).

No balanço energético realizado por Oliveira (2010) foi possível observar que o autor considerou o uso do bagaço de cana como fonte de eletricidade para o sistema produtivo. Machado (1998) relata que o excesso de bagaço de cana pode gerar eletricidade excedente, a qual pode ser vendida para a rede estadual. Caso essa energia excedente seja incluída no balanço energético do etanol, o valor do mesmo pode ultrapassar 10. Esse dado, no entanto, não foi comprovado por Oliveira (2010), que embora tenha considerado a eletricidade excedente foi constado um valor inferior ao mencionado por Machado (1998). É possível, porém, que o balanço mencionado por esse último autor não leve em consideração os efeitos ocasionados pela emissão de GEE, como considerou Oliveira (2010).

Excepcionalmente em relação aos efeitos ocasionados pela emissão de GEE, O que torna o etanol da cana atraente como um substituto para a gasolina é que ele é essencialmente um combustível renovável. $\mathrm{O}$ uso de etanol à base de cana-de-açúcar não resulta em uma emissão líquida significativa de GEE (principalmente $\mathrm{CO}_{2}$ ). A razão para isso é que o $\mathrm{CO}_{2}$ resultante da queima de etanol e do bagaço nas caldeiras é reabsorvido pela fotossíntese durante o crescimento da cana na próxima estação. Todas as necessidades de energia para a sua produção (calor e eletricidade) provêm do bagaço, cujo excesso pode ser usado para gerar eletricidade adicional, e consecutivamente, para alimentação na matriz produtora. Dessa maneira, consumo direto de combustíveis fósseis é limitado aos caminhões de transporte, máquinas de colheita e ao uso de fertilizantes, ao passo que o consumo indireto de combustíveis fósseis é baixo, devido ao fato da Matriz energética brasileira ser baseada principalmente na energia hidrelétrica (Goldemberg; Coelho e Guardabassi, 2008). Sob esse ponto de vista, Macedo et al. (2004) demonstram o equilíbrio de energia e GEE da produção de etanol produzido a partir de cana-de-açúcar (Tabela 7).

Tabela 7 - Balanço de energia e gases de efeito estufa da produção de etanol da cana-de-açúcar.

\begin{tabular}{cc}
\hline $\begin{array}{c}\text { Output/input de } \\
\text { Energia }\end{array}$ & $\begin{array}{c}\text { Emissão de GEE } \\
\left(\mathbf{k g} / \mathbf{m}^{\mathbf{3}}\right)\end{array}$ \\
\hline $8,3^{\mathrm{a}}$ & $389^{\mathrm{a}}$ \\
$10,2^{\mathrm{b}}$ & $359^{\mathrm{b}}$ \\
\hline
\end{tabular}

a Valores médios: cenário baseado nos valores médios de energia e consumo de material a partir de tecnologias produtoras precursoras. ${ }^{\mathrm{b}} \mathrm{Va}-$ lores altos: cenário baseado em valores de energia e consumo de material a partir do aprimoramento e desenvolvimento de novas tecnologias produtoras. Fonte: Macedo; Leal e Silva (2004)

Quando comparado ao etanol obtido a partir de outras fontes produtoras, o etanol de cana-de-açúcar possui um saldo de emissões de GEE inferior, conforme é possível observar na figura 7. Além desse fator, uma avaliação do ciclo de vida desenvolvida pela Ekos Brasil em 2006 mostrou que, ao substituir uma parcela de gasolina consumida na Suíça pelo etanol de cana-de-açúcar, o balanço energético é de 6.1, já incluída a energia consumida no transporte de etanol (Goldemberg; Coelho e Guardabassi, 2008; Rodrigues e Ortiz, 2016). Portanto, mesmo quando o etanol da cana é exportado para outros países, o balanço energético final é altamente positivo em comparação com outras culturas. Graças a esse equilíbrio energético positivo, o setor de açúcar/ etanol evita emissões equivalentes a $13 \%$ de todos os setores industriais, comerciais e residenciais brasileiros (Goldemberg; Coelho e Guardabassi, 2008). 


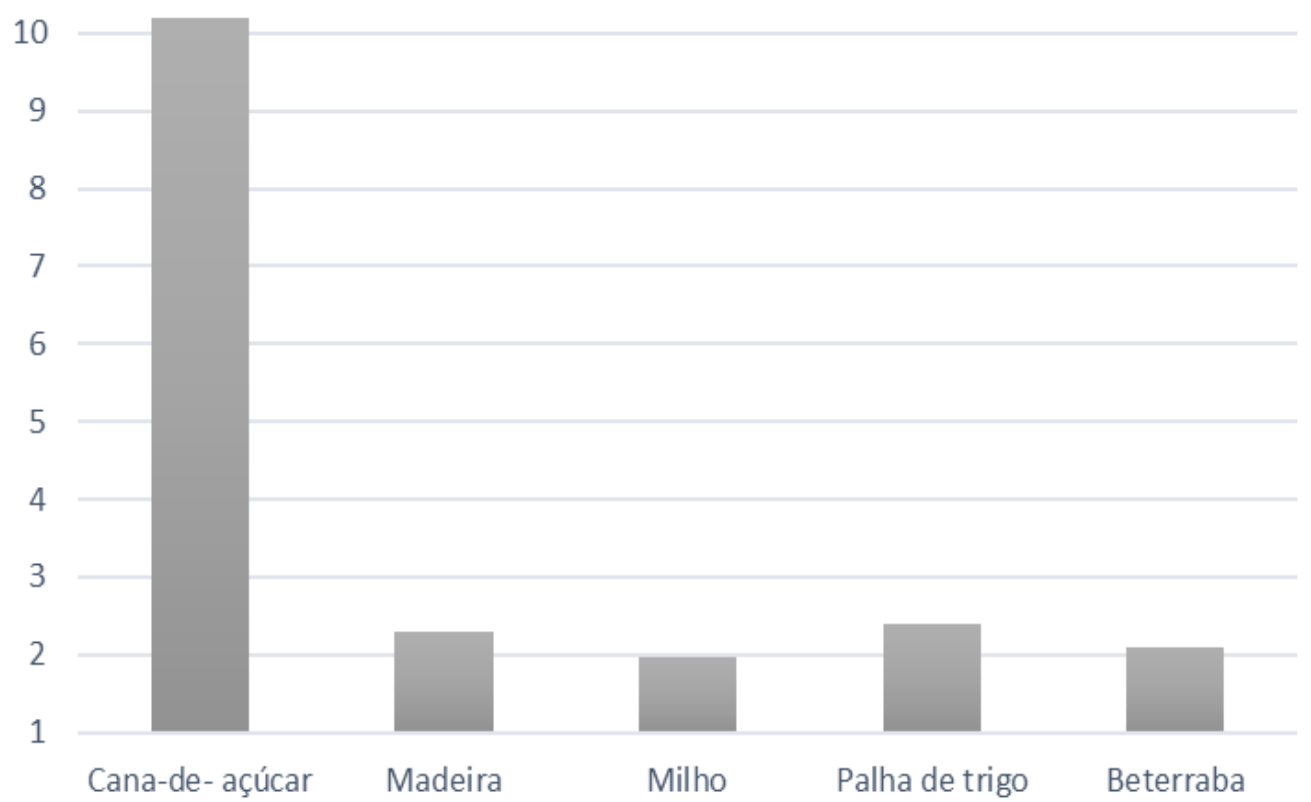

Fonte: Goldemberg; Coelho e Guardabassi (2008); Macedo (2007); Shapouri; Duffield e Wang (2002); Woods e Bauen (2003).

Figura 7 - Balanço energético da produção de etanol de diferentes matérias-primas. Os dados levam em consideração os valores output/input e os saldos de emissão de GEE.

Semelhante ao trabalho de Oliveira (2010), Grego (2011) também realizou um trabalho de comparação entre os balanços energéticos do etanol da cana e do milho. Analisando a eficiência energética e produtividade, a autora chegou a um balanço positivo para produção brasileira de etanol, o equivalente a 9,4, enquanto para a produção a partir do milho foi observado um balanço negativo de 0,8 .

Os dados levantados pela autora demonstraram uma diferença aproximada de 1,1 em relação aos dados apontados por Oliveira (2010) para o balanço energético do etanol obtido a partir da cana-de-açúcar. Os dados completos levantados pela autora estão dispostos na tabela 8 .

Tabela 8 - Incorporação e balanço energético para o etanol de cana-de-açúcar e de milho.

\begin{tabular}{l|c|c}
\multirow{2}{*}{ Componente do balanço energético } & \multicolumn{2}{|c}{ Valores } \\
\cline { 2 - 3 } & Cana-de-açúcar & Milho \\
\hline Produtividade (kg/ha) & 79.500 & 8.655 \\
Incorporação na produção agrícola (Mg/ha) & $12.329,70$ & $33.913,00$ \\
Incorporação na produção agroindustrial (MJ/ha) & $2.611,10$ & $54.941,60$ \\
Incorporação total (MJ/há) & $14.940,80$ & $88.854,60$ \\
Etanol produzido (L/há) & $6.510,00$ & $3.217,47$ \\
Energia contida no etanol (MJ) & $139.639,50$ & $69.014,73$ \\
\hline Balanço energético (input:output) & $\mathbf{9 , 4}$ & $\mathbf{0 , 8}$ \\
\hline
\end{tabular}

Fonte: Grego (2009)

Resultado semelhante ao observado por Grego (2011) também foi relatado por Soares et al. (2009). Com base nas informações disponibilizadas em 2009 no banco de dados do IBGE, os autores realizaram os cálculos para o balanço energético e encontraram um valor de 9,35 . O balanço calculado por eles considerou desde as operações agrícolas, passando pela análise completa do consumo de energia, na forma de óleo diesel combustível, até chegar nas etapas de processamento na usina. Os autores também supuseram que a colheita da cana ainda feita manualmente após queimada, o que ocorre em aproximadamente $60 \%$ da área canavieira nacional. No entanto, essa realidade vem sendo modificada pela introdução da colheita mecanizada, a qual segundo eles deverá aumentar o consumo de energia fóssil e, portanto, diminuir o balanço energético. Na tabela 9 tem-se o detalhamento do consumo de energia fóssil na etapa agrícola. 
Tabela 9 - Consumo de energia fóssil na etapa agrícola do etanol produzido a partir de cana-de-. Os valores estão expressos por hectare.

\begin{tabular}{l|c|c}
\hline Atividade & Quantidades & MJ/ha/ano \\
\hline Trabalhos & $64,0 \mathrm{~h}$ & 501,8 \\
Maquinas & $186,5 \mathrm{~kg}$ & $1.588,8$ \\
Óleo Diesel & $28,8 \mathrm{~L} \mathrm{~kg}$ & $1.383,7$ \\
Nitrogênio & $56,7 \mathrm{~kg}$ & $3.061,8$ \\
Fósforo & $16,0 \mathrm{~kg}$ & 51,0 \\
Potássio & $83,0 \mathrm{~kg}$ & 488,9 \\
Calcário & $367,0 \mathrm{~kg}$ & 478,9 \\
Sementes & $2.000,0 \mathrm{~kg}$ & 252,2 \\
Herbicidas & $3,20 \mathrm{~kg}$ & $1.445,3$ \\
Inseticidas & $0,24 \mathrm{~kg}$ & 87,3 \\
Aplicação da Vinhaça & $180 \mathrm{~m} 3$ & 656,0 \\
Transporte de insumo & $820,0 \mathrm{~kg}$ & 276,8 \\
Transporte da cana & $24,7 \mathrm{~L}$ & $2.058,0$ \\
Transporte total & & $2.334,8$ \\
Total das operações agrícolas & & $\mathbf{1 2 . 3 2 9 , 7}$ \\
\hline Entradas & & $\mathbf{M J} / \mathbf{h a} / \mathbf{a n o}$ \\
\hline Reagentes químicos usados na usina & Quantidades & 487,6 \\
Água & - & 0,0 \\
Cimento & $11,5 \mathrm{~kg}$ & 75,9 \\
Aço leve estrutural & $28,1 \mathrm{~kg}$ & 841,3 \\
Aço leve em equipamentos & $23,1 \mathrm{~kg}$ & 693,5 \\
Aço inoxidável & $4,0 \mathrm{~kg}$ & 287,1 \\
Retificação até 99,5\% & - & 225,3 \\
Tratamento de efluentes & - & 0,0 \\
Total de entradas na usina & - & $2.611,1$ \\
\hline Total de todas as entradas de energia fóssil & - & $\mathbf{1 4 . 9 4 0 , 8}$ \\
\hline
\end{tabular}

Fonte: Adaptado de Soares et al., (2009).

A partir dos dados demonstrados na tabela 9 os autores realizaram o cálculo do balanço energético, correspondendo ao total das operações agrícolas e as entradas de energia fóssil investida (Tabela 10).

Tabela 10 - Balanço energético do etanol produzido a partir de cana-de-açúcar nas condições brasileiras atuais

\begin{tabular}{lccc}
\hline Saídas & Quantidades & MJ/unidade & MJ/ha/ano \\
\hline Rendimento da cana-de-açúcar & $79,5 \mathrm{Mg} / \mathrm{ha}$ & & \\
Produção total de etanol & $6.510,0 \mathrm{~L} / \mathrm{ha}$ & 21,45 & $139.639,5$ \\
Balanço energético final & & & $\mathbf{9 , 3 5}$ \\
\hline
\end{tabular}

Fonte: Adaptado de Soares et al., (2009).

Entre os autores consultados, Soares et al., (2009) foram os únicos a apresentar um balanço energético de maneira a contemplar o estudo do ciclo de vida da produção do etanol, no qual incluiuse a energia fóssil empregada na fabricação, manutenção e possível desmontagem e disposição de equipamentos e construções utilizadas na manufatura de um produto. Todas essas etapas estão contabilizadas na Tab. 8, no item "máquinas", onde se incluem tratores e implementos agrícolas. Além dessa questão, os autores também foram os únicos a detalhar o processo empregado na colheita da cana, o que não foi mencionado pelos demais. No entanto, não se evidenciou a energia elétrica excedente como mencionou Oliveira (2010), o que poderia contribuir para um balanço energético maior. Além disso, o balanço realizado pelos autores foi realizado em um período no qual a colheita da cana era realizada após queimada do terreno, realizada superada atualmente.

Garcia et al. (2011) em trabalho realizado no México sobre a produtividade do etanol a partir da cana naquele país e utilizando o método do ciclo de vida, obteve uma quantidade de energia de 4,8 GJ para cada GJ gasto durante as etapas produtivas, o que corresponde a um balanço energético de 4,8 . O valor fornecido por esse autor mostrou-se inferior 
aos valores relatados por pesquisadores brasileiros. É necessário considerar nesse aspecto que as condições brasileiras de produção são mais favoráveis que as verificadas no México, uma vez que o Brasil é apontado como uma das maiores potências na produção de etanol a partir da cana, com uma tecnologia inovadora no ciclo produtor.

\section{Comparativo entre os balanços energéticos veri- ficados}

Na figura 8 tem-se o balanço energético verificado a partir das diferentes fontes de pesquisas consultadas, considerando cada atividade abordada pelo autor durante o cálculo. Com uma média de 6,74 , as divergências de valores são atribuídas às diferentes atividades consideradas por cada autor no desenvolvimento de seu balanço.

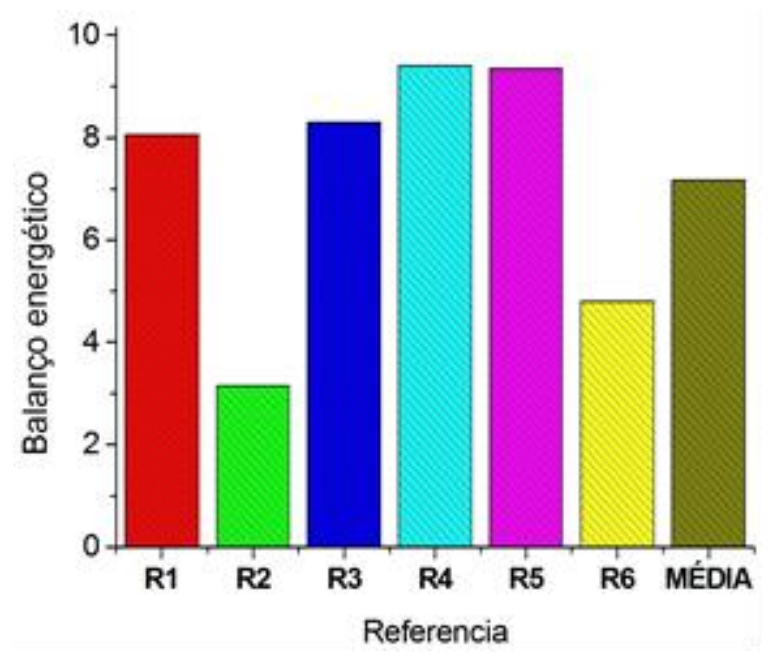

Figura 8 - Comparação entre os balanços energéticos verificados para o etanol de cana-de-açúcar. Dados: R1 (Urquiaga; Alves; Boodey, 2005); R2 (Santos; Santos, 2009); R3 (Oliveira, 2010); R4 (Grego, 2011); R5 (Soares et al., 2009) R6 (Garcia et al., 2011).

A partir da figura 8 é possível observar que o os dados levantados pelos autores Santos e Santos (2009) e Garcia et al., (2011) se mostraram abaixo da média global, tendo o primeiro apresentado uma diferença de quase $46 \%$ em relação á média verificada pelos demais autores. É preciso levar em consideração, no entanto, que o trabalho publicado por Santos e Santos (2009) foi realizado em cima da produtividade de uma micro destilaria, na qual se tem uma produtividade menor e um gasto energético diferenciado em relação às usinas maiores, que apresentam tecnologias mais sofisticadas para a produção. Por outro lado, como debatido anteriormente, os resultados demonstrados por Garcia et al., 2011 tem relação com o fato do México ser um país com pouco desenvolvimento em tecnologia sucroalcooleira, apresentando uma tecnologia produtiva menos eficiente.

Embora os principais dados mencionados sejam majoritariamente nacionais, exceto o trabalho de Garcia et al., (2011) e apresentem um balanço energético médio acima de 7 , alguns trabalhos publicados no exterior sobre o balanço energético do etanol produzido no Brasil trazem balanços energéticos baixos, entre 3,7 e 1,1, como sugeriram Pimentel e Patzek (2008) e Oliveira (2008). No entanto, os dados demonstrados por esses autores foram sustentados em informações defasados de uso de energia fóssil nas operações agrícolas, além de empregarem estimativas muito altas do custo energético do transporte da cana do campo até a usina, fatores que foram gradativamente melhorados até a produtividade atual.

\section{CONSIDERAÇÕES FINAIS}

O Brasil é apontado atualmente como o segundo maior produtor mundial de etanol e os valores das sagras atuais colaboram para a manutenção dessa posição. Dados sobre sua viabilidade e sustentabilidade energética são constantemente atualizados por diversos centros de pesquisa ao redor do mundo. Nesse aspecto, o estudo do balanço energético da produção brasileira é de suma importância, uma vez que visa estabelecer os fluxos de energia, identificando potenciais demandas e eficiências refletidas pelo ganho líquido e pela relação saída/entrada, o que determina a viabilidade ou não dos processos de obtenção de energia. Como observado durante o levantamento bibliográfico, não há consenso entre os principais autores quanto ao real balanço energético da produção de etanol. Assim, as principais divergências verificadas entre os podem ser explicadas pelo fato de nem todos terem considerado todas as atividades envolvidas na produção do etanol, sendo os gases de efeito estufa (GEE) e o ciclo de vida as atividades menos explorados, embora sejam as atividades que desempenham um dos papéis mais importantes para o cálculo do balanço energético e constatação da viabilidade e sustentabilidade energética da utilização do etanol como biocombustível renovável.

Os principais estudos realizados e levantados a partir da revisão realizada demonstraram que o etanol de cana-de-açúcar tem um balanço energético aproximadamente entre 8:1-9:1, ou seja, para cada unidade de energia fóssil gerada durante o processo produtivo são obtidas entre oito e nove unidades de energia renovável na forma de etanol. Esses dados refletem tanto as condições de São Paulo, que é apontado como um dos maiores produtores nacio- 
nais, devido às maiores áreas disponíveis para plantação, como nas demais áreas nacionais. Embora esse balanço seja positivo, fluxos de energia e determinação da eficiência energética visando á sustentabilidade da agricultura deve ser considerados continuamente, levando em conta que o balanço energético poderá decrescer nos próximos anos à medida que problemas ambientais relativos à produção agrícola forem surgindo. Esses problemas estão relacionados principalmente à compactação dos solos por tratores e implementos agrícolas, a contaminação de corpos d'água, lençóis freáticos e solos devido ao uso intenso de agrotóxicos e fertilizantes, aplicação descontrolada de vinhaça, torta de filtro, poluição do ar por queimadas de palha e escorias de siderurgia.

Diante do atual panorama da produção sucroalcooleria, reduzir a entrada de energia fóssil, especialmente aquela relacionada à aplicação de fertilizantes- apontado como um dos maiores gastos energéticos na matriz industrial- seria uma das primeiras alternativas para melhoria do balanço energético. Nesse contexto é preciso diminuir a quantidade a poluição de ar proveniente da queima do bagaço e palhada excedente para geração de energia elétrica e cinzas dessa queima, desenvolver sistemas eficientes para o descarte e aproveitamento adequado da água de lavagem da cana e de equipamentos, das águas residuais de condensadores e das águas residuais domésticas. Alternativas de mitigação, como biodegradação da vinhaça, reaproveitamento de subprodutos orgânicos, diminuição da produção de gases para geração de energia de maneira mais eficiente, diminuição do consumo e reuso da água, também podem ser destacados como alternativas para melhoria do balanço energético. Somente a atuação conjunta dessas ações poderão contribuir para que o etanol continue figurando entre as potenciais fontes alternativas de combustível, contribuindo para a sustentabilidade dos agroecossistemas como um todo.

\section{REFERÊNCIAS BIBLIOGRÁFICAS}

BNEF. Electric vehicles to be $35 \%$ of global new car sales by 2040. Disponível em: <https://about.bnef.com/blog/electric-vehicles-to-be-35-of-global-new-car-sales-by-2040/>.

CAMPOS, A.T.; CAMPOS, A.T. Balanços energéticos agropecuários: uma importante ferramenta como indicativo de sustentabilidade de agroecossistemas. Ciência Rural, v. 34, n. 6, p. 1977-1985, 2004.

CHECHETTO, R. G.; SIQUEIRA, R.; GAMERO, C.A. Balanço energético para a produção de biodiesel pela cultura da mamona (Ricinus communis L.). Revista Ciencia Agronomica, v. 41, n. 4, p. 546-553, 2010.

COELHO, S. T. et al. Brazilian sugarcane ethanol: lessons learned. Energy for Sustainable Development, v. 10, n. 2 , p. 26-39, 2006.
CONAB. Acomapanhamento da safra brasileira de açúcarSafra 2015/16. 2. ed. Brasília: Companhia Nacional de Abastecimento, 2015.

CONAB. Cana-de- açúcar: Acompanhamento da safra brasileira. Disponível em: <http://www.conab.gov.br/OlalaCMS/uploads/arquivos/17_08_24_08_59_54_boletim_cana_portugues_-_2o_lev_-_17-18.pdf $>$.

DEPEC. Acúcar e Etanol- Junho de 2017. Disponível em: $<$ https://www.economiaemdia.com.br/EconomiaEmDia/pdf/infset_acucar_etanol.pdf>. Acesso em: 7 nov. 2017.

FIESP/ICONE. Outlook Brasil 2022- Projeções para o Agronegócio. 1. ed. São Paulo: FIESP/ICONE, 2012.

GAZZONI, D. L. et al. Balanço energético da cultura da canola para a produção de biodiesel Canola energy balance for biodiesel production. Espaço Energia, v. 1, n. 11, p. 25-28, 2009.

GOLDEMBERG, J.; COELHO, S. T.; GUARDABASSI, P. The sustainability of ethanol production from sugarcane. Energy Policy, v. 36, n. 6, p. 2086-2097, 2008.

HANDLER, R. M. et al. Life Cycle Assessments of Ethanol Production via Gas Fermentation: Anticipated Greenhouse Gas Emissions for Cellulosic and Waste Gas Feedstocks. Industrial and Engineering Chemistry Research, v. 55, n. 12, p. 3253-3261, 2016.

LARSON, E. D. A review of life-cycle analysis studies on liquid biofuel systems for the transport sector. Energy for Sustainable Development, v. 10, n. 2, p. 109-126, 2006.

MACEDO, I. D. C.; LEAL, M. R. L. V.; SILVA, J. E. A. R. DA. Assessment of greenhouse gas emissions in the production and use of fuel ethanol in Brazil. São Paulo: [s.n.]. Disponível em: <http://www.wilsoncenter.org/sites/default/files/brazil.unicamp.macedo.greenhousegas.pdf $>$.

MACEDO, I. DE C. Sugar Cane's energy: Twelve studies on Brazilian sugar cane. São Paulo: [s.n.].

MORAES, B. S.; ZAIAT, M.; BONOMI, A. Anaerobic digestion of vinasse from sugarcane ethanol production in Brazil: Challenges and perspectives. Renewable and Sustainable Energy Reviews, v. 44, p. 888-903, 2015.

NANDA, S. et al. An assessment on the sustainability of lignocellulosic biomass for biorefining. Renewable and Sustainable Energy Reviews, v. 50, p. 925-941, 2015.

OLIVEIRA, E.C. Balanço energético na produção de álcool da cana-de-açúcar: comparativo com a produção norte americana de etanol por meio da utilização de milhoDouradosTrabalho de conclusão de curso, Universidade Estadual de Mato Grosso do Sul. Dourados - MS, 2010, , 2010.

OLIVEIRA, L.M.; SERRA, J.C.V.; OLIVEIRA, K.B.M. Balanços energéticos da produção de etanol para diferentes matérias primas. Revista Eletrônica do Curso de Geografia - Geoambiente On-line, v. 1, n. 22, p. 39-52, 2014.

RFA. 2017 Ethanol Industry Outlook. United States: [s.n.] Disponível em: <http://www.ethanolrfa.org/resources/publications/outlook/>.

RODRIGUES, D.; ORTIZ, L. Em direção à sustentabilidade da produção de etanol de cana de açúcar no Brasil. [s.l: s.n.]. Disponível em: <http://www.ecoa.org.br/arqui- 
vos/444052181.pdf\%5Cnhttp://ndt.oxfordjournals.org/lookup/doi/10.1093/ndt/gfw346\%5Cnhttp://www. scielo.br/pdf/jbpneu/v30n2/v30n2a15>.

SHAPOURI, H.; DUFFIELD, J. A.; WANG, M. The energy balance of corn ethanol: An updateUSDA- United States Departent of Agriculture. Washington: [s.n.].

SOARES, L. H. DE B.; ALVES, B. J. R.; URQUIAGA, S.; BODDEY, R. M. Mitigação das emissões de gases efeito estufa pelo uso de etanol da cana-de-açúcar produzido no Brasil. Circular técnica, p. 14, 2009.

UNIT STATION. Transforming our world: the 2030 Agenda for Sustainable Development. World Health, v. 16301, n. October, p. 1-15, 2015.

URQUIAGA, S.; ALVES, B. J. R.; BOODEY, R. M. Produção de biocombustíveis A questão do balanço energético. Revista de Política Agrícola, v. 14, n. 1, p. 42-46, 2005.

URQUIAGA, S.; BOODEY, R. M. Produção de biocombustíveis A questão do balanço energético. p. 42-46, 2005.

WOODS, J.; BAUEN, A. Technology status review and carbon abatement potential of renewable transport fuels in the UK. UK: [s.n.]. Disponível em:

<http://www.fcrn.org.uk/sites/default/files/DTI_Technology_status_review.pdf $>$. 